\title{
Aminopyrine breath test in alcoholic liver disease and in patients on enzyme-inducing drugs
}

\author{
K. O. LEWIS, GEOFFREY NICHOLSON, P. LANCE, AND A. PATON \\ From the Departments of Clinical Chemistry and Clinical Investigation, Dudley Road Hospital, \\ Birmingham B18 7QH, UK
}

SUMMARY The ${ }^{14} \mathrm{C}$-aminopyrine breath test was used to measure liver function in 14 normal subjects, 16 patients with alcoholic cirrhosis, 14 alcoholics without cirrhosis, and 29 patients taking a variety of drugs. The normal value for the breath test was $8.6 \pm 1.5 \%$, whereas it was significantly lower $(5 \cdot 1 \pm 3.8 \%)$ in patients with alcoholic cirrhosis. Higher than normal values were found in some alcoholic patients without cirrhosis and in patients receiving enzyme-inducing drugs, such as phenobarbitone. There was a significant correlation between serum gamma-glutamyltransferase and breath test in these groups. Some patients with alcoholic cirrhosis may also be capable of enzyme induction.

The assessment of hepatic function by breath analysis after the oral administration of (dimethylamine-14 C)aminopyrine has been described by two groups (Hepner and Vesell, 1975; Bircher et al., 1976a; Lauterburg and Bircher, 1976). The test is based on the fact that aminopyrine is metabolised primarily in the liver with conversion of the ${ }^{14} \mathrm{C}$-labelled methyl groups to ${ }^{14} \mathrm{CO}_{2}$ and that the concentration of ${ }^{14} \mathrm{CO}_{2}$ in the breath is related to the rate of aminopyrine metabolism (Hepner and Vesell, 1974; Bircher et al., 1976b). It involves the oral administration of a trace dose of ${ }^{14} \mathrm{C}$-labelled aminopyrine and collection of a breath sample for analysis at two hours (Hepner and Vesell, 1975). Hepner found a highly significant correlation between the two-hour ${ }^{14} \mathrm{CO}_{2}$ output and the aminopyrine metabolic clearance rate in control subjects and cirrhotic patients (Hepner and Vesell, 1974). We have used the test to assess liver function and, in particular, to assess the effects of alcohol and drugs on the liver.

\section{Patients and methods}

The following groups were studied:

116 patients with histologically confirmed alcoholic cirrhosis. Four of these were taking enzymeinducing drugs (phenobarbitone, phenytoin).

220 alcoholics without clinical evidence of cirrhosis, attending an addiction unit. All had been drinking over 10 pints (about 6 litres) of beer or its equivalent daily for at least two years

Received for publication 4 April 1977 and had been abstinent for less than two weeks (mean $7 \pm 4$ days) at the time of study. Liver biopsies in 19 were either normal or showed variable degrees of fatty change, portal inflammation or fibrosis. One patient refused biopsy.

328 patients on long-term drugs-barbiturates (11), corticosteroids (12), opiate addicts (5).

414 control subjects who were either healthy colleagues (7) or patients who did not have liver disease and were not taking drugs (7).

Informed consent was obtained from all those tested.

BREATH TEST TECHNIQUE (Hepner and Vesell, 1975)

An oral dose of $1.5 \mu \mathrm{Ci}$ (dimethylamine- ${ }^{14} \mathrm{C}$ )aminopyrine (Amersham, specific activity $12.2 \mathrm{mCi}$ / mmol, $98 \%$ radiochemically pure) was given in water without previous fasting, and the subject was asked to rest quietly. Two hours later breath was collected by blowing through $4 \mathrm{ml} \mathrm{M}$ hyamine hydroxide-ethanol in a glass scintillation vial until the thymol-phthalein indicator showed a sudden colour change from blue to colourless. This indicated that $2 \mathrm{mmol} \mathrm{CO}_{2}$ had been collected. After addition of scintillation cocktail the ${ }^{14} \mathrm{CO}_{2}$ was counted and specific activity calculated. The cumulative excretion in the two-hour period was calculated by multiplying the specific activity by the endogenous output of carbon dioxide (ie, $9 \mathrm{mmol} \mathrm{kg^{-1 } \mathrm { h } ^ { - 1 }}$ (Winchell et al., 1970) ) and expressed as a percentage of the administered dose. 
SERUM ENZYMES

Serum gamma-glutamyltransferase EC2.3.2.2. $(\gamma-\mathrm{GT})$ was assayed with the Boehringer kit using gammaglutamyl $p$-nitranilide as substrate (normal range: $<40 \mathrm{IU} / 1$ ); alkaline phosphatase by the Technicon SMA method using $p$-nitrophenylphosphate as substrate (normal range: 20-120 IU/1).

\section{Results (Figs. 1 and 2)}

The mean ${ }^{14} \mathrm{CO}_{2}$ excretion of the 16 patients with cirrhosis $(5 \cdot 1 \pm 3 \cdot 8 \%)$ was significantly lower than that $(8.6 \pm 1.5 \%)$ of the control group (P > 0.01) despite four cirrhotics who had values in the high normal range; these were the patients taking enzymeinducing drugs. Four out of five patients with ${ }^{14} \mathrm{CO}_{2}$ excretion below $2.5 \%$ died during the eight months of the study. The scatter of ${ }^{14} \mathrm{CO}_{2}$ excretion in 20 alcoholics without permanent liver damage was very wide but the mean value of $10.6 \pm 2.6 \%$ was significantly above the mean control value $(\mathrm{P}<0.05)$.

The mean figures for $\mathrm{CO}_{2}$ excretion in patients taking barbiturates, corticosteroids, and opiates were respectively $15.2 \pm 4.0 \%, 11.6 \pm 1.4 \%$, and $10 \cdot 1 \pm 2.0 \%$. These were significantly different from normal at levels of $P<0.001, P<0.01$, and $P<0.05$ respectively.

There was a significant correlation between ${ }^{14} \mathrm{CO}_{2}$ excretion and serum $\gamma$-GT in patients taking barbiturates (Fig. 3) but not in those receiving corticosteroids. The number of opium addicts was too small to allow analysis.

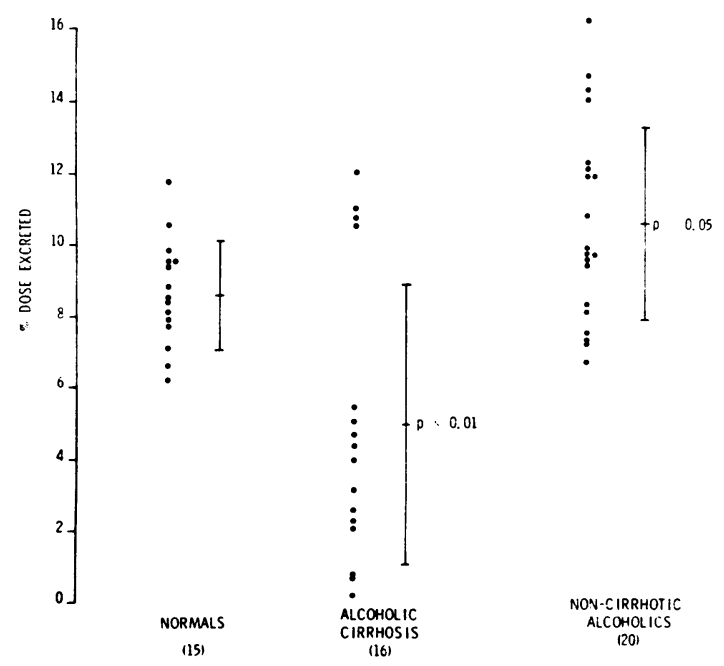

Fig. 1 Two-hour ${ }^{14} \mathrm{CO}_{2}$ excretion as a percentage of the oral dose in normal subjects and in alcoholic liver disease (mean $\pm 1 S D)$.

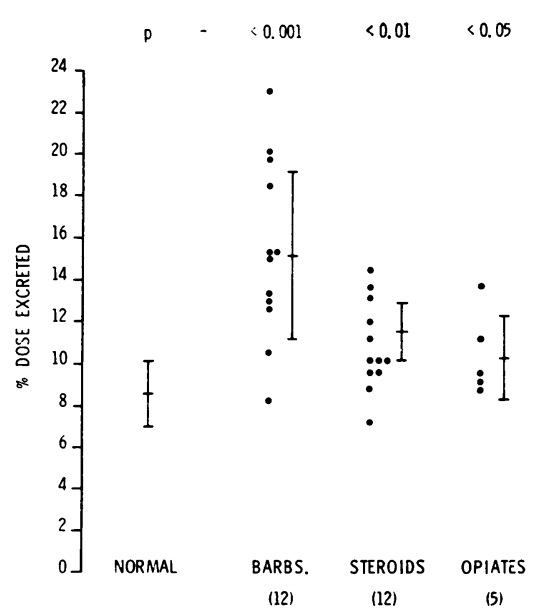

Fig. 2 Two-hour ${ }^{14} \mathrm{CO}_{2}$ excretion as a percentage of the oral dose in patients on enzyme-inducing drugs $($ mean $\pm 1 S D)$.

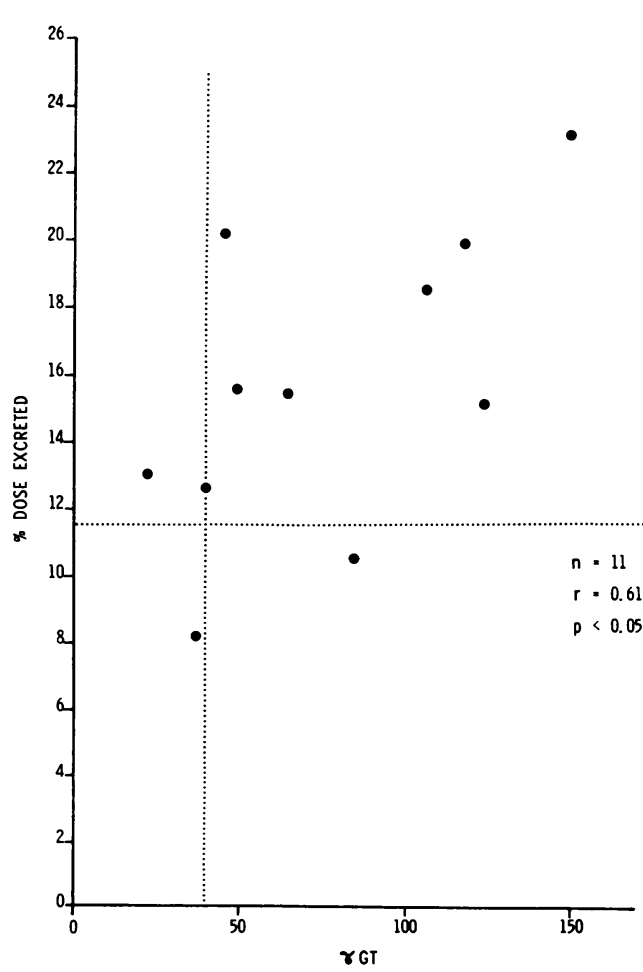

Fig. 3 Relationship between breath test values and serum $\gamma-G T$ levels for patients taking barbiturates. 
Cirrhotic patients had raised serum alkaline phosphatase levels (mean $292 \pm 219 \mathrm{IU} / \mathrm{l}$ ) and greatly raised $\gamma$-GT (mean $283 \pm 253 \mathrm{IU} / \mathrm{l}$ ), and there was no correlation between $\gamma$-GT and ${ }^{14} \mathrm{CO}_{2}$ excretion.

${ }^{14} \mathrm{CO}_{2}$ excretion did not correlate with serum $\gamma-\mathrm{GT}$ in the non-cirrhotic alcoholic patients. When the four patients with alkaline phosphatase greater than $120 \mathrm{IU} / 1$ were excluded the mean values for alkaline phosphatase and $\gamma$-GT were $78 \pm 19$ and $139 \pm 85 \mathrm{IU} / 1$ respectively, and there was a significant correlation between ${ }^{14} \mathrm{CO}_{2}$ excretion and $\gamma$-GT $(r=0.50, \mathrm{P}<0.05)$.

\section{Discussion}

We have confirmed that, in general, patients with cirrhosis have a reduced ${ }^{14} \mathrm{CO}_{2}$ excretion after ${ }^{14} \mathrm{C}$-aminopyrine administration. Moreover, the test may have some prognostic value, since the lowest values were found in patients who died of liver failure during the course of the study. It is cheap, easy to perform, non-invasive, and acceptable to patients. The dose of radiation is $0 \cdot 5-2.5 \mathrm{mrem}$ (comparable to a routine diagnostic chest radiograph), and repeated tests can be done in the same patient.

We had expected to find values intermediate between the normal and the cirrhotic groups (Hepner and Vesell, 1975) in alcoholics without permanent liver damage. Such patients, however, often had increased ${ }^{14} \mathrm{CO}_{2}$ excretion and this correlated with the serum $\gamma$-GT level in those patients with normal serum alkaline phosphatase. Exclusion of the patients with raised total alkaline phosphatase removes those with an obstructive cause for a raised $\gamma$-GT (Ceriotti, 1976) but may not remove all such cases, for Brohult and Sundblad (1973) have demonstrated cholestasis in alcoholics with normal total alkaline phosphatase by the presence of alpha-1 phosphatase isoenzyme in their serum. Prolonged consumption of alcohol increases hepatic mixedfunction oxidase activity (Lieber, 1973), shortens the half-life of several drugs (Misra et al., 1971), and raises the serum $\gamma$-GT level even when other liver function tests are normal (Rosalki and Rau, 1972). It has been suggested (Rosalki, 1975) that the sensitivity of serum $\gamma$-GT to heavy alcohol consumption is in part due to $\gamma$-GT induction in the hepatic microsomes and also to hepatic microsomal injury by alcohol. The significant correlation between the breath test and serum $\gamma$-GT in patients taking barbiturates, which are known to cause up to three-fold increases in $\gamma$-GT, suggests that the increase in breath test values is due to enzyme induction, and this may also be the explanation for the findings in alcoholics without permanent liver damage.

Although several methods exist for the measurement of enzyme induction, none is entirely satisfactory (Neale, 1975). Nevertheless, we believe that the high ${ }^{14} \mathrm{CO}_{2}$ excretion found in some of the patients may provide a pointer to enzyme induction. It is of considerable interest that the four patients with cirrhosis who had high values for ${ }^{14} \mathrm{CO}_{2}$ excretion were all taking enzyme-inducing drugs, and this suggests that the diseased liver may still be capable of increasing its rate of drug metabolism (Levi et al., 1968).

We thank Dr M. I. Akhter for access to his patients at the Drug Addiction Unit.

\section{References}

Bircher, J., Küpfer, A., Gikalov, I., and Preisig, R. (1976a). Aminopyrine demethylation measured by breath analysis in cirrhosis. Clinical Pharmacology and Therapeutics, 20, 484-492.

Bircher, J., Platzer, R., Gikalov, I., Küpfer, A., and Preisig, R. (1976b). Aminopyrine breath test for evaluation of liver function. How to analyse the ${ }^{14} \mathrm{CO}_{2}$ data. Radioaktive Isotopen in Klinik und Forschung, 12, 3478 (English).

Brohult, J., and Sundblad, L. (1973). Isoenzyme patterns of serum alkaline phosphatase in ethanol-induced liver injury. Acta Medica Scandinavica, 194, 497-499.

Ceriotti, G. (1976). A new look at the measurement and interpretation of enzyme assays. Annals of Clinical Biochemistry, 13, 345-353.

Hepner, G. W., and Vesell, E. S. (1974). Assessment of aminopyrine metabolism in man by breath analysis after oral administration of ${ }^{14} \mathrm{C}$-aminopyrine. New England Journal of Medicine, 291, 1384-1388.

Hepner, G. W., and Vesell, E. S. (1975). Quantitative assessment of hepatic function by breath analysis after oral administration of $\left[{ }^{14} \mathrm{C}\right]$ aminopyrine. Annals of Internal Medicine, 83, 632-638.

Lauterburg, B. H., and Bircher, J. (1976). Expiratory measurement of maximal aminopyrine demethylation in vivo: effect of phenobarbital, partial hepatectomy, portacaval shunt and bile duct ligation in the rat. Journal of Pharmacology and Experimental Therapeutics, 196, 501-509.

Levi, A. J., Sherlock, S., and Walker, D. (1968). Phenylbutazone and isoniazid metabolism in patients with liver disease in relation to previous drug therapy. Lancet, 1, 1275-1279.

Lieber, C. S. (1973). Liver adaptation and injury in alcoholism. New England Journal of Medicine, 288, 356-362.

Misra, P. S., Lefèvre, A., Ishii, H., Rubin, E., and Lieber, C. S. (1971). Increase of ethanol, meprobamate and pentobarbital metabolism after chronic ethanol administration in man and in rats. American Journal of Medicine, 51, 346-351. 
Neale, G. (1975). In Modern Trends in Gastroenterology, Vol. 5, edited by A. E. Read, p. 266. Butterworths, London.

Rosalki, S. B. (1975). Gamma-glutamyl transpeptidase. Advances in Clinical Chemistry, 17, 53-107.

Rosalki, S. B., and Rau, D. (1972). Serum $\gamma$-glutamyl- transpeptidase activity in alcoholism. Clinica Chimica Acta, 39, 41-47.

Winchell, H. S., Stahelin, H., Kusubov, N., Slanger, B., Fish, M., Pollycove, M., and Lawrence, J. H. (1970). Kinetics of $\mathrm{CO}_{2}-\mathrm{HCO}_{3}^{-}$in normal adult males. Journal of Nuclear Medicine, 11, 711-715. 